\title{
Interleukin 25 (IL-25) expression in cholangiocarcinoma
}

\author{
SUPAKIT KAEWSARABHUMI $^{1}$, TANAKORN PROUNGVITAYA ${ }^{1,2}$, TEMDUANG LIMPAIBOON $^{1,2}$, \\ PATCHARAPORN TIPPAYAWAT ${ }^{1,2}$, DOUNGDEAN TUMMANATSAKUN ${ }^{1,2}$, ATTAPOL TITAPUN $^{2,3}$, \\ PRAKASIT SA-NGAIMWIBOOL ${ }^{2,4}$ and SIRIPORN PROUNGVITAYA ${ }^{1,2}$
}

\begin{abstract}
${ }^{1}$ Centre of Research and Development of Medical Diagnostic Laboratories (CMDL), Faculty of Associated Medical Sciences; ${ }^{2}$ Cholangiocarcinoma Research Institute (CARI), Faculty of Medicine; Departments of ${ }^{3}$ Surgery and ${ }^{4}$ Pathology, Faculty of Medicine, Khon Kaen University, Khon Kaen 40002, Thailand
\end{abstract}

Received August 26, 2019; Accepted June 2, 2020

DOI: $10.3892 / \mathrm{mco} .2020 .2154$

\begin{abstract}
Various cytokines are involved in carcinogenesis and tumor progression. Some tumor cells produce cytokines by themselves. Using secretome analysis, a high expression of APEX-1 was found in cholangiocarcinoma (CCA) cell lines. During this secretome analysis, it was found that CCA cell lines overexpressed some cytokines and related molecules, including interleukin 25 (IL-25). In the present study, we first performed precise secretome analysis on cytokines and related molecules in CCA cell lines and identified that IL-25 was overexpressed in CCA cell lines. Then, using immunohistochemical methods, we investigated the expression of IL-25 in the cancer tissues from 20 CCA patients in Northeast Thailand. Correlation between IL-25 expression levels and patients' clinical parameters were analyzed. The results showed that IL-25 expression was significantly $(\mathrm{P}<0.0001)$ higher in cancerous tissues than in the normal bile ducts and in the adjacent tissues. Overexpression of IL-25 protein in CCA tissue was confirmed using western blot analysis. Moreover, IL-25 expression in cancerous tissues was significantly $(\mathrm{P}<0.0015)$ higher in CCA patients with metastasis than in CCA patients without metastasis. Survival analysis revealed that a high expression of IL-25 was correlated with shorter survival time of CCA patients $(\mathrm{P}=0.0260)$. Aberrant expression of IL-25 in CCA tissue was associated with tumor metastasis and poor prognosis, suggesting that IL-25 is a potential prognostic biomarker. Biological roles of IL-25 in CCA genesis and progression should be explored in future.
\end{abstract}

Correspondence to: Dr Siriporn Proungvitaya, Centre of Research and Development of Medical Diagnostic Laboratories (CMDL), Faculty of Associated Medical Sciences, Khon Kaen University, 123 Mittraphap Road, Khon Kaen 40002, Thailand

E-mail: sirpat@kku.ac.th

Key words: cholangiocarcinoma, interleukin-25, metastasis, prognosis, tissue, immunohistochemistry

\section{Introduction}

Cholangiocarcinoma (CCA) is the most common cancer in the Northeast Thailand, especially in Khon Kaen region, although the global incidence of CCA is low $(1,2)$. CCA is a malignant transformation of bile duct epithelium and can be anatomically classified into intrahepatic and extrahepatic types (3). While the former type is common in the Greater Mekong Subregion including Northeast Thailand, in relation to infection with carcinogenic liver fluke, Opisthorchis viverrini, the latter is common in the rest of the world (4). Currently CCA patients are treated with surgery, radiotherapy and chemotherapy. However, prognosis of intrahepatic CCA patients is extremely poor because intrahepatic CCA is a silent tumor with rapid growth and frequent metastasis, and reliable diagnostic markers have yet to be identified $(4,5)$. CCA genesis and progression are multifactorial events. In liver fluke infection-associated intrahepatic CCA, inflammatory cytokines, especially IL-6, play roles in carcinogenesis and tumor progression $(6,7)$. However, little is known about the contribution of other cytokines to CCA genesis and progression.

IL-25, also known as IL-17E, is a newly identified member of the IL-17 family of inflammatory cytokines (8). It is produced by Th-17 cells and many other cells, including mast cells, alveolar macrophages, eosinophils and intestinal and respiratory epithelial cells $(9,10)$. IL-25 can induce the production of various Th2-type cytokines such as IL-4, IL-5 and IL-13, which are the key regulators of inflammatory and autoimmune diseases $(9,11)$. In relation to cancer, IL-25 produced from tumor-associated fibroblasts can suppress metastasis of mammary tumor (12). Presence of IL-25 producing tumor-associated macrophages is a predictor for the good prognosis of gastric cancer (13). According to 'A pathology atlas of the human cancer transcriptome' by Uhlen et al, several cancer types including CCA were positive for IL-25 protein (14). In a previous study, using secretome analysis of three CCA cell lines and one immortile cholangiocyte cell line MMNK-1, it was found that APEX-1 was overexpressed in CCA cell lines and serum APEX-1 level was a potential biomarker for CCA (15). In that study, several cytokines including IL-25 and some cytokine-related molecules were upregulated in CCA cell lines. 
In this study, therefore, using the same secretome database, we first carried out a precise analysis on the expression levels of cytokines and cytokine-related molecules in CCA cell lines. The results showed that 6 cytokines and related molecules were overexpressed in at least 2 of 3 CCA cell lines with the predominant overexpression of IL-25. Then, using immunohistochemistry, we examined IL-25 expression in CCA tissues and found that IL-25 expression was significantly higher in the cancerous tissue compared with the adjacent non-cancerous tissue. In addition, the overexpresison of IL-25 in CCA was associated with metastatic status and poor prognosis of CCA patients.

\section{Patients and methods}

Patients and specimens. The paraffin-embedded pathologically confirmed CCA tumor tissue specimens from 20 patients were provided by the Cholangiocarcinoma Research Institute (CARI), Faculty of Medicine, Khon Kaen University, Thailand. The patients underwent surgery at the Srinagarind Hospital, Khon Kaen University, between November 2010 and June 2012. According to reports from pathologists, 13 out of 20 patients were positive for lymph node metastasis while 7 patients were negative for metastasis. In addition, 15 fresh frozen CCA tissues together with the sera of corresponding patients were also provided from CARI and Khon Kaen University (KKU), for protein extraction. Tissues and sera that were used in this study were all left-over specimens obtained during surgical treatment. Written informed consent for the use of left-over specimen for research purpose was obtained from the attending physicians prior to surgery and the original copies of the documents were kept in CARI and KKU. This series of experiments haves been approved (HE571283) by the Ethics Committee of Khon Kaen University, Thailand, and all specimens were anonymously coded according to the guidelines. Required sample size of CCA tissues was calculated using PS: Power and Sample Size Calculation version 3.1.2., Department of Biostatistics, Vanderbilt University (16).

Candidate protein selection. To identify overexpressed proteins secreted from CCA cells, previously we constructed a secretome database from three CCA cell lines, KKU-213A, KKU-213B and KKU-100, and a control immortalized cholangiocyte cell line, MMNK1 (17). In brief, the cell lines were cultured in Ham's F-12 culture medium supplemented with $10 \%$ fetal bovine serum, $100 \mathrm{U} / \mathrm{ml}$ of penicillin and $100 \mu \mathrm{g} / \mathrm{ml}$ of streptomycin at $37^{\circ} \mathrm{C}$ in $5 \% \mathrm{CO}_{2}$ air atmosphere. When the cells were grown to $70 \%$ confluency, they were extensively washed with PBS followed by serum-free medium. Then, the cells were incubated in $12 \mathrm{ml}$ of serum-free medium in $15-\mathrm{cm}$ dishes for $24 \mathrm{~h}$. The conditioned media containing secreted proteins were harvested and centrifuged at $600 \mathrm{x}$ g for $10 \mathrm{~min}$ to remove cell debris. The conditioned medium samples were concentrated and desalted using Amicon ultra-15 tubes (MW cut-off $3 \mathrm{kDa}$ ), centrifuged at $4,000 \mathrm{x}$ for $50 \mathrm{~min}$ at $4^{\circ} \mathrm{C}$, and the supernatants were stored as secretome samples at $-20^{\circ} \mathrm{C}$ until use.

Fifty micrograms of the secretome samples $(15 \mu \mathrm{g}$ protein each) were dissolved in sample buffer, boiled for $5 \mathrm{~min}$, and were separated on 12.5\% SDS-PAGE (ATTO AE-6530 system). After electrophoresis, the gel was fixed, sensitized with $0.02 \% \mathrm{Na}_{2} \mathrm{~S}_{2} \mathrm{O}_{3}$ for $2 \mathrm{~min}$, and then stained with silver nitrate solution $\left(0.2 \% \mathrm{AgNO}_{3}\right)$ and color developing solution. The stained gel was washed and scanned using a GS-710 scanner (Bio-Rad) and stored in $0.1 \%$ acetic acid until use.

For in-gel tryptic digestion, the gel lanes were divided into 5 wide ranges according to the standard protein markers and then sub-divided into 15 ranges. Each gel range was chopped into small sections $\left(1 \mathrm{~mm}^{3} /\right.$ section), and transferred to 96 -well plate (5-10 sections/well). The gel sections were dehydrated twice in $100 \%$ acetonitrile and cysteine bonds were reduced with dithiothreitol, and then alkylated with $100 \mathrm{mM}$ iodoacetamide. After reduction and alkylation, the gel sections were dehydrated with $100 \%$ acetonitrile and tryptic digestion was performed overnight at room temperature. The digested peptides were extracted from the gel three times. Finally, the tryptic peptide mixtures were dried and kept at $-80^{\circ} \mathrm{C}$.

LC-MS/MS analysis. The extracted peptides sample was dissolved in $15 \mu \mathrm{l}$ of $0.1 \%$ formic acid, centrifuged at $12,000 \mathrm{x} \mathrm{g}$ for $5 \mathrm{~min}$ at $37^{\circ} \mathrm{C}$, and then injected into LC-MS/MS system. Briefly, the peptides were separated using a Dionex-Ultimate 3000 LC System. The mobile phase A $(0.1 \%$ formic acid $)$ and the mobile phase $\mathrm{B}(0.1 \%$ formic acid in $50 \% \mathrm{ACN})$ were used to elute peptides using a multistep gradient of 10-70\% of mobile phase $\mathrm{B}$ at $0-13 \mathrm{~min}$ (the time-point of retention), $90 \%$ of mobile phase B at 13-15 min, followed by a decrease to $10 \%$ of mobile phase B at 15-20 min. Peptide fragment mass spectra were acquired in data-dependent AutoMS mode with a scan range of $300-1,500 \mathrm{~m} / \mathrm{z} ; 3$ averages and up to 5 precursor ions selected from the MS scan of $50-3,000 \mathrm{~m} / \mathrm{z}$.

DeCyderMS differential analysis software (DeCyderMS, GE Healthcare) was used for the quantitation of peptides based on MS precursor signal intensities of individual LC-MS spectra. The quantitation of peptides was performed using the PepDetect module. From the secretome database analyses using the PepDetect and PepMatch modules followed by the Mascot software search, we identified that 1,138 proteins were commonly upregulated in at least two CCA cell lines compared with those of MMNK1 cells.

Of 1,138 proteins, six proteins were identified as cytokine and cytokine-related molecules (IL-28A, interferon-stimulated exonuclease, IL-25 isoform 1 , Dermokine- $\beta 2$, TGF- $\beta 1$ and C-C chemokine receptor type 1) (Table I).

Immunohistochemistry. The sections of 20 paraffin-embedded CCA tissues were cut at $4 \mu \mathrm{m}$ thickness and deparaffinized by soaking in xylene for $2 \mathrm{~min}$, and rehydrated in a descending series of ethanol (absolute, 95 and 70\%) and then transferred into citrate buffer ( $\mathrm{pH}$ 6.0). The sections in citrate buffer were boiled for $10 \mathrm{~min}$ and washed in PBS. Endogenous peroxidase activity of the sections was blocked with $3 \% \mathrm{H}_{2} \mathrm{O}_{2}$ in methanol for $1 \mathrm{~h}$ in the dark and then non-specific background binding was blocked with $20 \%$ fetal bovine serum for $2 \mathrm{~h}$. The sections were incubated with $150 \mu \mathrm{l}$ of rabbit polyclonal antibody against human IL-25 (Biorbyt) at 1:300 dilution at $4^{\circ} \mathrm{C}$ overnight. A tissue section for the representative of negative control skipped this step. The sections were washed in PBS-T and incubated with $150 \mu \mathrm{l}$ of peroxidase-labelled goat anti-rabbit Ig antibody of the EnVision System DakoCytomation Inc.) 
Table I. Expression levels of the cytokine-related molecules from the secretome data of fold difference in CCA cell lines compare with control.

Cell line

\begin{tabular}{lccc} 
& KKU-100 & KKU-213A & KKU-213B \\
\cline { 2 - 4 } Secreted proteins & $6.9^{\mathrm{a}}$ & $0.7^{\mathrm{a}}$ & $7.6^{\mathrm{a}}$ \\
\hline IL-25 isoform 1 precursor & 2.4 & 1 & 4 \\
IL-28A & -2.4 & -0.8 & -2 \\
Interferon stimulated exonuclease & 1.4 & 1.6 & -0.9 \\
Dermokine- $\beta 2$ & -0.2 & -0.8 & 1.3 \\
TGF- $\beta$ 1 & 0.3 & 2.5 & 0.6 \\
C-C chemokine receptor type 1 &
\end{tabular}

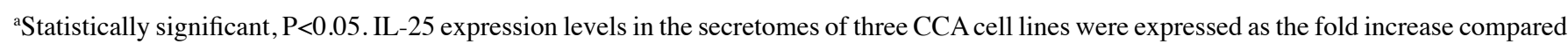
against that in the secretome of immortalized cholangiocyte cell line, NMMK-1. CCA, cholangiocarcinoma.

for $1 \mathrm{~h}$ and developed the signal using 3,3'-diaminobenzidine (DakoCytomation) for $5 \mathrm{~min}$ in the dark. The sections were washed with running tap water until clear and counterstained with hematoxylin for $10 \mathrm{~min}$. The sections were dehydrated in the ascending series of ethanol and cleared in xylene. Finally, the sections were mounted with Permount ${ }^{\circledR}$ and sealed with a cover glass (18).

Evaluation of IL-25 expression in CCA tissues by immunohistochemistry. The staining patterns of IL-25 protein in CCA tissues were assessed microscopically at magnification, $\mathrm{x} 400 \mathrm{using} \mathrm{H}$-score, recording both the intensity of staining ( 0 , no staining; $1+$, weak staining; $2+$, moderate staining; and 3+, strong staining) and the percentage of tumor cells stained (0-100\%) leading to the range of $\mathrm{H}$-score $0-300$ to each sample. The results were read around 10 fields per sample to decrease variation of detection. The H-score was calculated as a sum of the intensity as follows; $\mathrm{H}$-score $=(\%$ of positively stained tumor cells at weak intensity $\mathrm{x} 1)+(\%$ of positively stained tumor cells at moderate intensity $\times 2)+(\%$ of positively stained tumor cells at strong intensity x3). Lastly, H-scores of 10 fields were averaged (19).

Protein extraction from surgical specimen of CCA. The methods for protein extraction from solid tissues followed those described previously (20-22). Approximately 100-200 mg of freshly frozen cancerous and its adjacent noncancerous tissues were obtained from 15 cases of human CCA surgical materials. The tissues were separately washed with ice-cold phosphate-buffered saline (PBS, 0.1 M sodium phosphate, $0.15 \mathrm{M}$ sodium chloride, $\mathrm{pH}$ 7.2) to remove any blood clots and excess connective tissues. Proteins were extracted using a T-PER ${ }^{\mathrm{TM}}$ Tissue Protein Extraction Reagent for Tissue (Thermo Fisher Scientific). Firstly, tissue lysis buffer was prepared by adding the protease inhibitor cocktail (cOmplete ${ }^{\mathrm{TM}}$, Roche) and phosphatase inhibitor cocktail (PhosSTOP ${ }^{\text {TM }}$, Roche) to the T-PER reagent just before use according to the manufacturer's instructions with some modifications. In brief, human CCA and adjacent non-cancerous tissues were separately minced in $500 \mu \mathrm{l}$ each of the tissue lysis buffer and approximately 40-80 dounce strokes were carefully homogenized on ice (23).
The tubes were centrifuged at $3,000 \times \mathrm{g}$ for $5 \mathrm{~min}$ at $4^{\circ} \mathrm{C}$ to spin down unbroken tissues and cell debris. The supernatants were collected and protein contents were determined using the Bradford protein assay (Thermo Fisher Scientific) method (24).

Western blot analysis. To investigate IL-25 protein expression in CCA and adjacent non-cancerous tissues by semi-quantitative, western blotting with $B$-actin as a loading control was performed. All 15 samples of cancerous and noncancerous tissue proteins (30 $\mu \mathrm{g}$ protein for each sample) were mixed with $4 \mathrm{X}$ loading dye at 1:4 proportion, and boiled for $5 \mathrm{~min}$. The protein samples were loaded on $12.5 \%$ SDS-PAGE and run at $150 \mathrm{~V}$ for $1 \mathrm{~h}$ in the cold room. The electrophoresis was completed when the dye reached the end of the gel, and the separated proteins were transferred onto PVDF membrane at $300 \mathrm{~V}$ for $1 \mathrm{~h}$ at room temperature. The membrane was blocked with $5 \%$ skim-milk in 1X TBST for $1 \mathrm{~h}$ at room temperature. The membrane was then incubated with 1:500 dilution of a primary antibody, rabbit polyclonal antibody against human IL-25 (Biorbyt) overnight at $4^{\circ} \mathrm{C}$. Next, the membrane was washed 3 times with $1 \mathrm{X}$ TBST for $10 \mathrm{~min}$ each, then incubated with 1:10,000 dilution of horseradish peroxidase-conjugated goat anti-rabbit IgG-secondary antibody for $1 \mathrm{~h}$ at room temperature, followed by washing 3 times with 1X TBST 10 min each. Finally, the chemiluminescence was detected using an ECL plus system (GE Healthcare) and visualized using Amersham Imager 600.

Potential interaction analysis. Potential interaction of the identified protein was analyzed using the public-domain software STITCH 5.0, the search tool for interacting chemicals known as STITCH 5.0 (date of access: 11/02/2019) $(25,26)$. Interaction was performed for IL-25 signaling, which correlated with the metastatic pathway. In brief, a set of input page icons of the software was shown at the start page. The page icon named 'multiple names' was selected. The list of proteins of interest was keyed in, e.g., IL-25 and/or other specified metastatic proteins and an item 'Homo sapiens' was selected as the organism, and then 'SEARCH' was clicked. The new popup page with the list of the protein names of interest, for example IL-25, and other proteins were identified and 'Continue' was clicked. The subsequent popup new page showed the confidence view. 
Statistical analyses. Statistical analyses were performed using SPSS v.16.0 software (SPSS Inc.) and GraphPad Prism v.5 software (GraphPad Software Inc.). The data were presented as mean $\pm \mathrm{SD}$ and the range (minimum to maximum). Shapiro Wilk and Kolmogorov Smirnov normality tests were used to check normal distribution of the data. The statistical difference between groups was determined using an unpaired t-test. The correlation between groups was investigated using Pearson's correlation. Cumulative survival time was calculated using a Kaplan-Meier method and analyzed by log-rank test. $\mathrm{P}<0.05$ was considered to indicate a statistically significant difference.

\section{Results}

Selection of IL-25 from secretome database analysis. Inflammatory cytokines play key roles in CCA carcinogenesis (7). We identified 6 cytokine-related molecules which were over-expressed in the secretomes of CCA cell lines compared with the immortal cholangiocyte cell line, MMNK1. Those are interleukin 25 isoform 1 (IL-25), interleukin 28A (IL-28A), interferon-stimulated exonuclease gene 20 (ISG20HEM45CD25), dermokine- $\beta 2$, transforming growth factor beta 1 (TGF- $\beta 1$ ) and CC chemokine receptor (CCR) type 1 (Table I). Of those, IL-25 was found to be the most overexpressed cytokine at least in two CCA cell lines, KKU-100 and KKU-213B. Although IL-28A was also overexpressed, the degree of overexpression of IL-28A was far less than that of IL-25. Thus, IL-25 was chosen for further analysis.

Immunohistochemical detection of IL-25 protein in CCA tissues. IL-25 expression was investigated for 20 CCA tissues using immunohistochemistry, and the representative images of negative control, cancerous area and adjacent area of CCA tissues are shown in Fig. 1. Fig. 1A is a negative control staining of CCA tissue. In the adjacent area to the CCA tissue, a monolayer of normal cholangiocytes of the bile duct epithelium were stained with pale brown (Fig. 1B). In cancerous area, CCA cells were stained with dark brown in color showing high expression of IL-25 in the cytoplasm (Fig. 1C). The scatter plot revealed that the mean $\mathrm{H}$ score of cancerous tissues was significantly higher $(\mathrm{P}<0.0001)$ than that of the normal bile ducts in the adjacent non-cancerous tissue (Fig. 1D).

Since IL-25 is known to play a role in tumor metastasis $(7,20)$, CCA patients were divided into two groups, those with and without metastasis, and IL-25 expressions levels in the cancerous area of both groups were compared. As shown in Fig. 1E, IL-25 expression level in cancerous area of the patients with metastasis group was significantly higher $(\mathrm{P}=0.0015)$ than that of the non-metastasis group. When IL-25 expression levels in cancerous and non-cancerous tissues of these two groups were compared, cancerous tissues were overexpressed as compared to the metastasis group and the difference was statistically significant (Fig. 1F, P<0.0001) but not in the non-metastasis group (Fig. $1 \mathrm{G}, \mathrm{P}=1.6490$ ).

IL-25 protein levels in CCA tissues. Fifteen frozen tissue specimens were used to determine IL-25 protein expression in cancerous and non-cancerous areas of CCA tissues. The proteins were extracted from each pair of tissues separately and western blot analysis was performed. The results revealed that IL-25 protein was strongly expressed in all 15 cancerous tissues but not in the adjacent non-cancerous tissues (Fig. 2A), similar to the IHC results. The relative intensity of IL-25 protein levels in cancerous tissues was higher than that of the adjacent non-cancerous tissues (Fig. 2B). The IL-25 expression levels via western blot analysis were correlated well with the expression levels determined by IHC (Fig. 2C).

Association between IL-25 expression in CCA tissues and the clinical parameters of the patients. To determine the association between IL-25 expression in CCA tissues and clinical parameters of the patients, CCA patients were divided into high and low IL-25 expression groups using the median value (265.71) of the $\mathrm{H}$ score of all $20 \mathrm{CCA}$ specimens as the cut-off value. Then, the patients' clinical parameters were compared between high and low IL-25 expression groups. The results showed that a higher IL-25 expression was significantly associated with high frequency of lymph node metastasis and shorter survival time $(\mathrm{P}=0.0369, \mathrm{P}=0.0232$; Table II $)$.

Survival time analysis of CCA patients. Since the mean survival time of CCA patients was significantly shorter in patients with high IL-25 expression in CCA tissues, the overall survival (OS) of the patients in relation to IL-25 expression level in CCA tissues was analyzed using a Kaplan-Meier method and log-rank test. The results showed that patients with a high IL-25 expression had shorter OS than those with a low IL-25 expression ( $\mathrm{P}=0.0260$; Fig. 3).

IL-25 protein interaction. To determine the potential role of IL-25 in CCA metastasis, possible interaction of IL-25 with cancer metastasis-related proteins was predicted using STITCH version 5.0 (Fig. 4). The results showed that IL-25 directly interacted with SMAD family member 2 (SMAD2) and indirectly interacted with transforming growth factor-beta 1 (TGF- $\beta 1$ ). The expression of the TGF- $\beta$ family signaling molecule SMAD2 and TGF- $\beta 1$ could elevate levels of IL-25 (27). Moreover, the results revealed that nuclear factor kappa-light-chain-enhancer of activated B cells (NF- $\mathrm{B})$, Snail homolog 1 (Drosophila; SNAI 1) and epithelial-mesenchymal transition (EMT) were indirectly interacted with IL-25 with the high confidence score $>0.7$ (Fig. 4). Thus, SNAI 1 was enhanced by NF- $\mathrm{B}$ and SNAL 1-induced EMT involved the loss of E-cadherin and claudins with concomitant upregulation of vimentin and fibronectin, among other biomarkers; EMT is associated with metastasis (28).

\section{Discussion}

IL-25 is a newly identified inflammatory cytokine involved in inflammation and autoimmune diseases (13). It is produced not only from immune or inflammatory cells but also from epithelial cells. IL-25 protein is also detected in several types of cancer (14), tumor-associated microenvironments and implicated in tumor progression (12,29-32). In this study, using immunohistochemical methods, we clearly demonstrated that IL-25 is overexpressed in the majority of CCA tissues. Overexpression of IL-25 in CCA is correlated with lymph node metastasis and shorter survival time of the patients. 
Table II. Comparison of patients clinical parameters between high IL-25 expression and low IL-25 expression groups ${ }^{\mathrm{a}}$.

\begin{tabular}{lccc}
\hline Clinical parameters & Low IL-25 expression ${ }^{\mathrm{b}}$ (median) & High IL-25 expression $^{\mathrm{b}}$ (median) $^{\text {P-value }^{\mathrm{c}}}$ \\
\hline Age (years) & 56 & 59.5 & 0.6228 \\
Lymph node metastasis & $1 / 10$ & $10 / 10$ & $0.0369^{\mathrm{a}}$ \\
Survival time (days) & 784 & 203 & $0.0232^{\mathrm{a}}$ \\
Aspartate aminotransferase (U/l) & 45.5 & 120.5 & 0.1403 \\
Alanine aminotransferase (U/l) & 35 & 73 & 0.3443 \\
Alkaline phosphatase (U/l) & 161 & 140 & 0.5966 \\
Total bilirubin (mg/dl) & 0.7 & 2.35 & 0.3237 \\
Direct bilirubin (mg/dl) & 0.3 & 1.5 & 0.1486 \\
Total protein (mg/dl) & 7.4 & 7.85 & 0.5964 \\
Albumin (mg/dl) & 3.9 & 3.7 & 0.9395 \\
Globulin (mg/dl) & 3.2 & 3.45 & 0.9397 \\
Cholesterol (mg/dl) & 183.5 & 184 & 0.9397
\end{tabular}

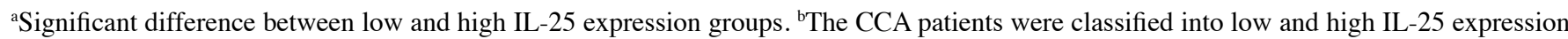
groups using the median value of $\mathrm{H}$-score of $20 \mathrm{CCA}$ specimens. ${ }^{\mathrm{c}}$ Statistical significance at $\mathrm{P} \leq 0.05$ (Mann-Whitney test).

A

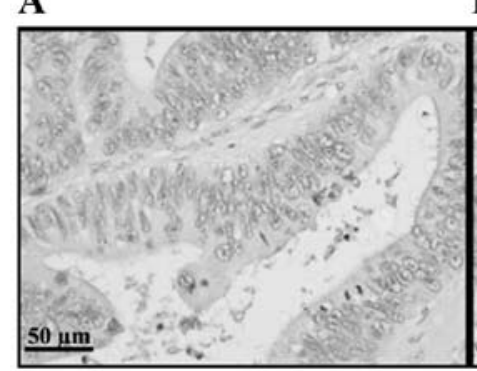

B

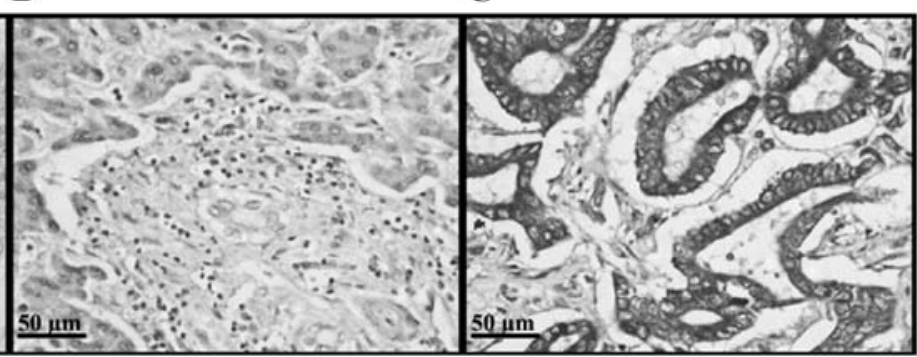

D

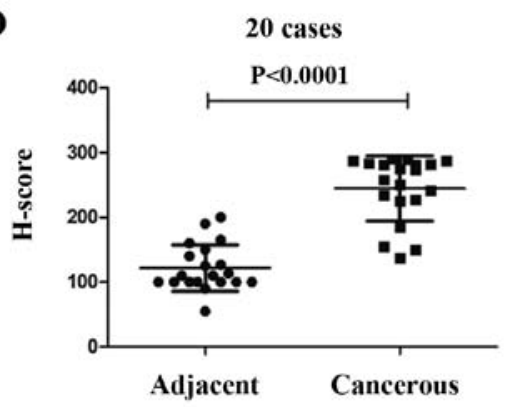

F

Metastasis CCA

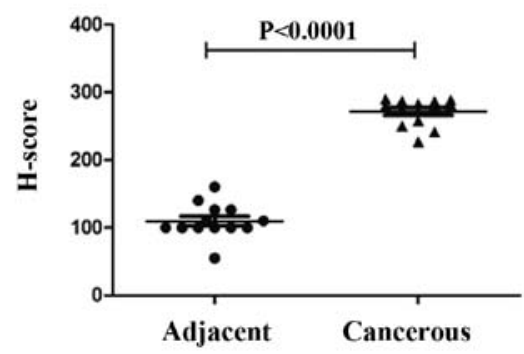

E

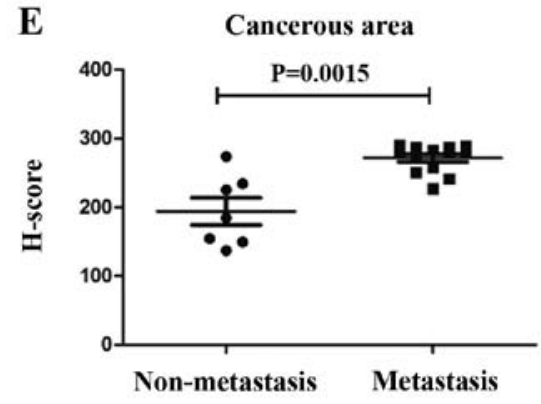

G

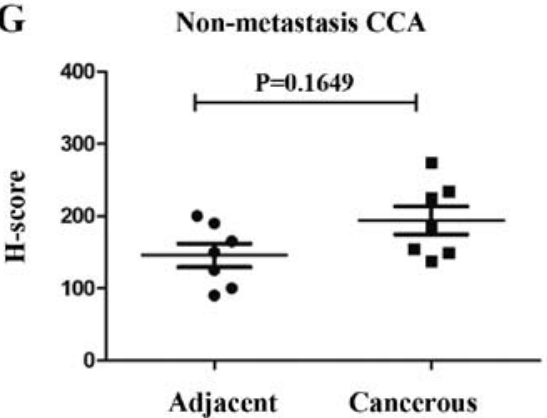

Figure 1. Immunohistochemical detection of IL-25 in surgically obtained cholangiocarcinoma tissues. (A) The negative control of CCA tissue without primary antibody. (B) Weak IL-25 staining of normal monolayer of cholangiocytes in normal tissues adjacent to CCA tissue. (C) Strong cytoplasmic staining in CCA cells. (D) The expression of IL-25 in cancerous region was higher than adjacent region with statistical significance (P<0.0001). (E) IL-25 expression in cancerous regions of metastasis group was higher than the non-metastasis group with statistical significance $(P=0.0015)$. $(F$ and $G)$ The scatter plots show that the expression of IL-25 was higher in cancerous tissue than in adjacent tissue $(\mathrm{P}<0.0001)$, whereas such a difference was not seen in non-metastasis group. Data were presented as mean \pm SEM. 
A

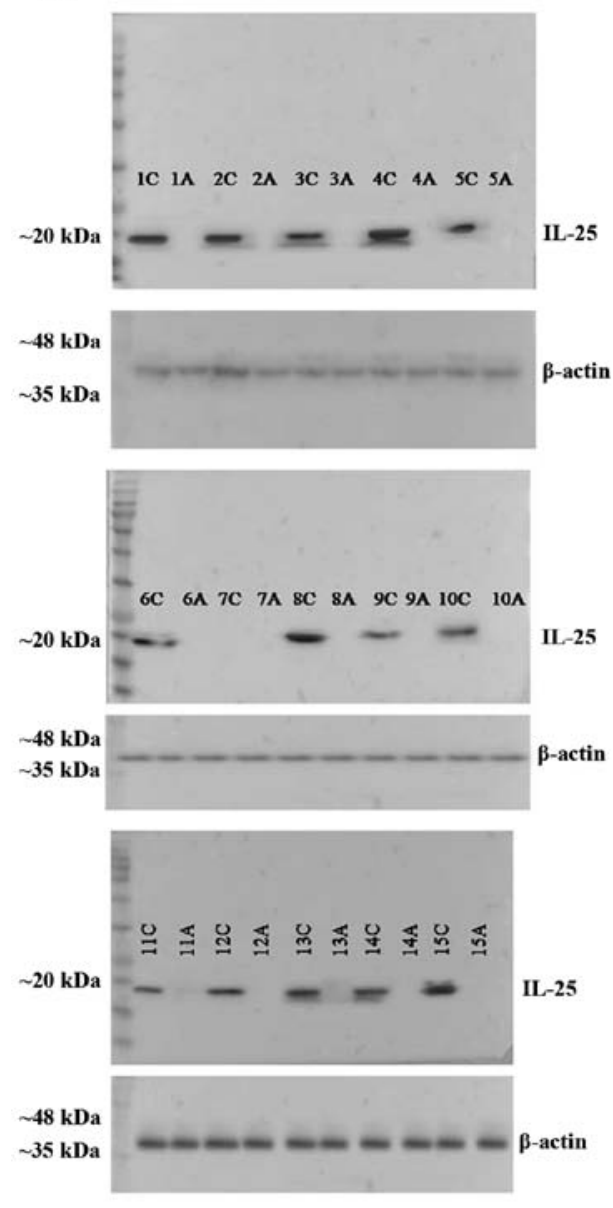

B

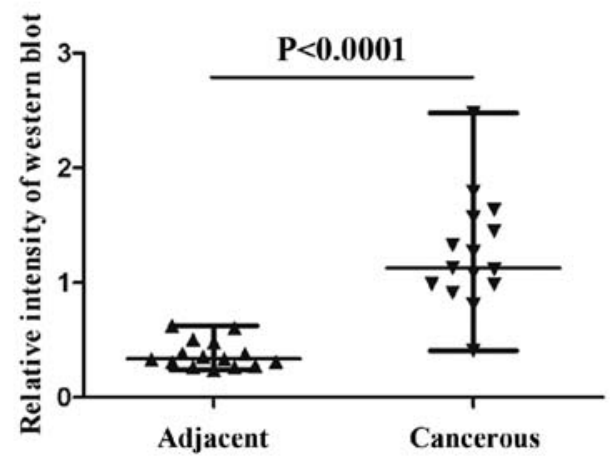

C

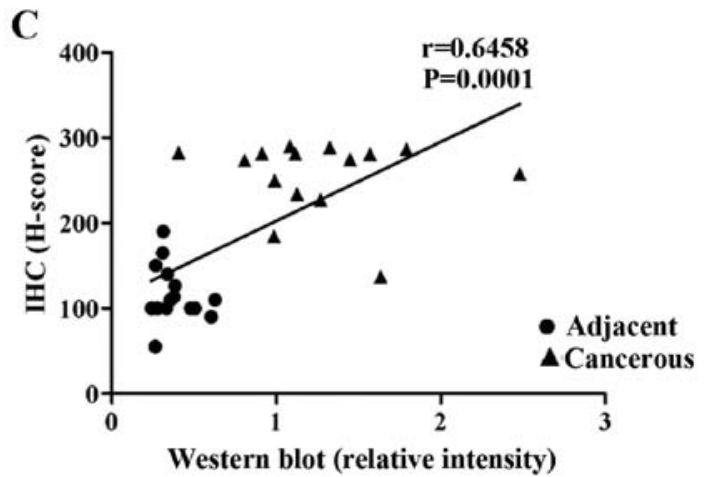

Figure 2. The relative intensity of western blot for IL-25 in CCA tissue. A total of 15 fresh frozen surgical specimens of CCA were used. IL-25 protein levels of each pair of tissue extracts from cancerous and non-cancerous tissues were semi-quantitatively analysed using western blot analysis. The result of IL-25 from frozen tissues between cancerous and adjacent noncancerous tissues (C; cancerous, A; adjacent). (B) IL-25 expressed in adjacent and cancerous tissues and the relative intensity showed adjacent IL-25 levels were lower than cancerous tissues. (C) Correlation of IL-25 between IHC and western blotting ( $\mathrm{r}=0.6458, \mathrm{P}=0.0001)$.

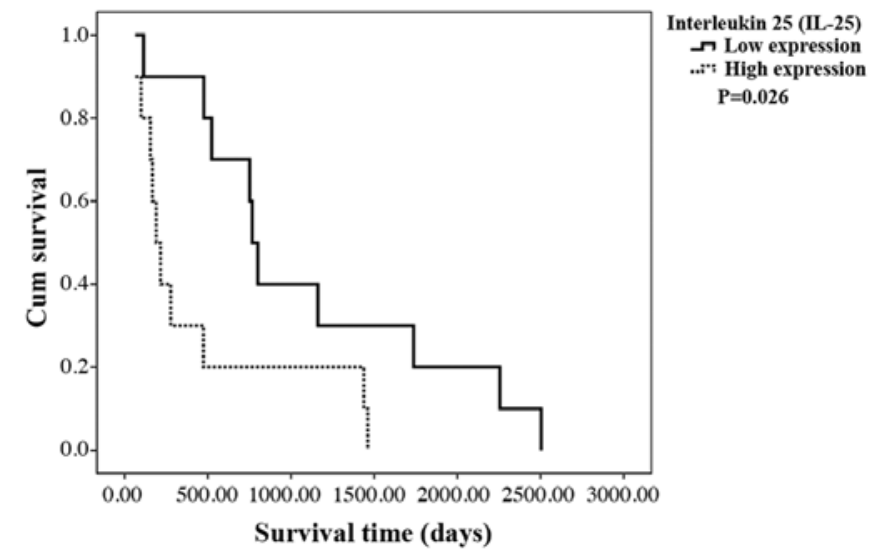

Figure 3. The Kaplan-Meier survival curve of CCA patients with low (dark line) and high (dashed line) expression of IL-25 in the tumor tissue. The Kaplan-Meier survival curves of CCA patients with low ( $\mathrm{N}=10$, dark line) and high ( $\mathrm{N}=10$, dashed line) expression of IL-25 in the tumor tissue. Patient with a high IL-25 expression in cancerous region has significantly shorter $(\mathrm{P}=0.0260)$ survival than the low IL-25 group (log-rank test).

As was suggested by Ji and Zhang, the role of Th17 cells including IL-25 producing cells in cancer is a disputable topic (31). In particular, IL-25 is produced, not only by immune inflammatory cells but also by mucosal epithelial cells and also by some cancer cells, as mentioned earlier. In this study, IHC and western blot analysis revealed active IL-25 production by the majority of CCA cancer cells compared with the adjacent non-cancerous tissues. Although we have not quantified, accumulation of IL-25 producing immune/inflammatory cells was not clearly seen in the cancer stroma. Thus, IL-25 from CCA cells may exert its regulatory role on cancer cells themselves on the one hand, while simultaneously modulating immune inflammatory cells in the tumor microenvironment. Thus, the role of IL-25 in cancer should be analyzed for both the producing and target cells.

IL-25 produced and secreted from CCA cells may confer its regulatory function on tumor cells in various ways. The simplest explanation is that, as with other cytokines, it may directly act as an autocrine or paracrine hormone to regulate biological function of CCA cells. To test this possibility, IL-25 receptor expression on CCA cells should be determined. While our present results suggested growth promotion activity of IL-25 to CCA cells, Furuta et al reported that IL-25 can induce caspase-dependent apoptosis of IL-25R-positive breast cancer (32). Antitumor activity of IL-17E (IL-25) against human melanoma, colon adenocarcinoma, NSCLC, breast cancer, pancreatic cancer was demonstrated in murine xenograft model (33). 


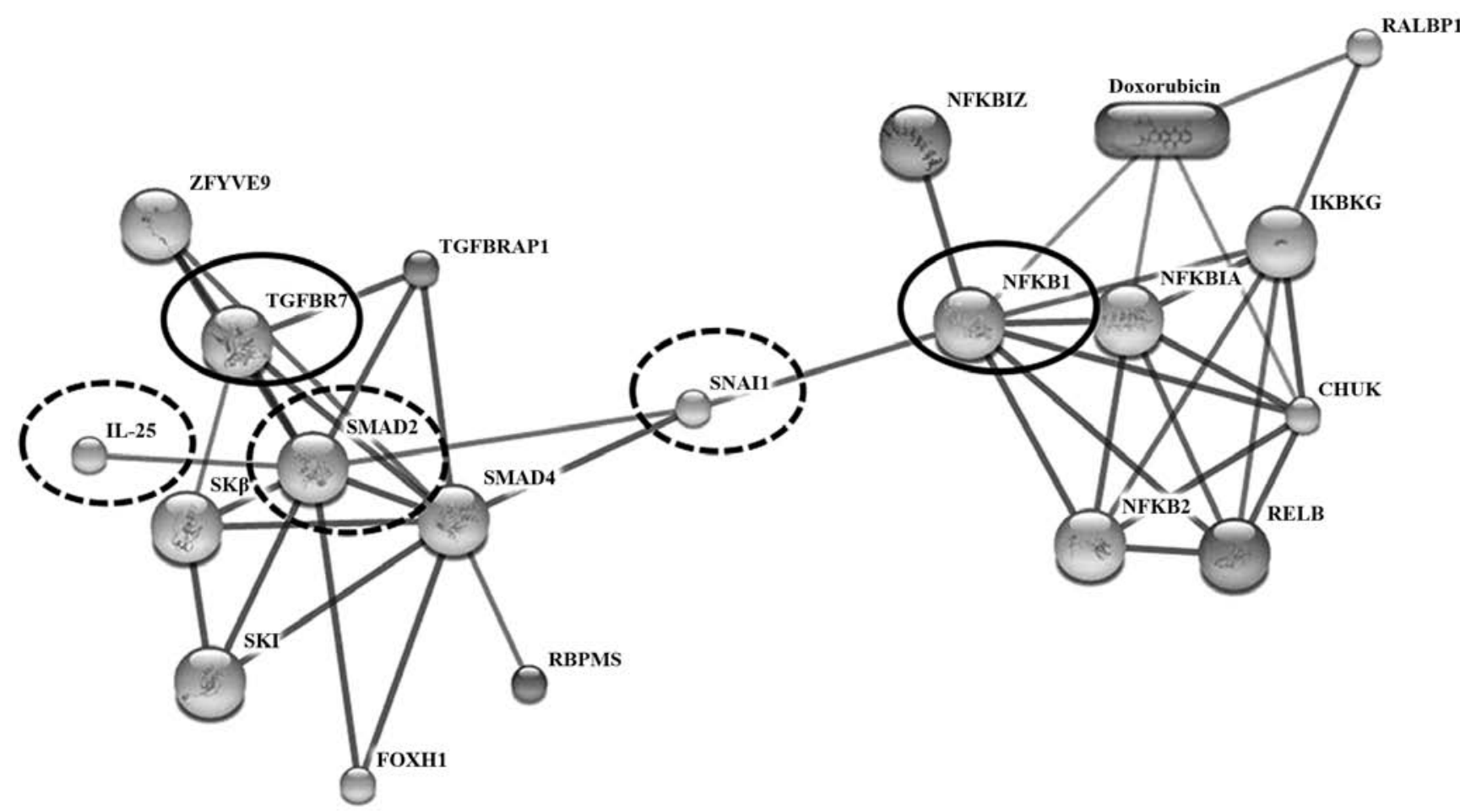

Figure 4. The interaction of IL-25 and metastasis-related proteins. To interpret the confidence view, stronger associations are represented by the thicker lines. Protein-protein interactions are shown in solid lines. In our study, highly confident interaction was focused with a score $>0.7$. Filtering interactions network was according to transcription factor (in bold oval; NF- $\kappa \mathrm{B}$ ), transforming growth factor (in bold oval; TGF- $\beta$ receptor 1 ) and metastasis-associated proteins (dashed oval; IL-25, SMAD 2, SNAI 1) were predicted by STITCH Version 5.0 (http://stitch.embl.de). IL-25 is associated with SMAD2, nuclear factor kappa-light-chain-enhancer of activated B cells (NF- $\mathrm{B}$ ), transforming growth factor beta (TGF- $\beta 1$ ), and snail homolog 1 (Drosophila; SNAI1).

Alternatively, IL-25 from CCA cells may modulate tumor microenvironment in various ways. For example, IL-25 activates innate lymphoid cells (ILCs) which promote organ fibrosis (34). Periductal fibrosis is a hallmark of CCA genesis in association with elevation of serum IL-6 levels. However, IL-6 was not detected in our secretome database (6). IL-25 is known to promote airway angiogenesis in asthmatic patients (35). IL-17 (including IL-17E/IL-25) promotes non-small cell lung cancer (NSCLC) growth via angiogenesis (36).

In the present study, a high expression of IL-25 in CCA cells is associated with tumor metastasis and shorter survival time of the patients. Concerning the role of IL-25 in tumor metastasis, Jiang et al (30) demonstrated a critical role of IL-25 in promoting tumor metastasis through modulating type 2 immune response via targeting Th 2 cells in breast cancer model. They also found that IL-25 was expressed in all four major histopathological types of human breast cancer (29). In addition, in gastric cancer, the degree of infiltration of IL-25-positive tumor-associated macrophages in tumor tissues is correlated with the longer overall survival (13).

STITCH analysis for the interaction of IL-25 with other molecules supported our results that IL-25 correlated with molecules involved in tumor metastasis. IL-25 pathway induces activation of $\mathrm{NF}-\kappa \mathrm{B}(37)$. $\mathrm{NF}-\kappa \mathrm{B}$ is known as a pivotal regulator of the epithelial mesenchymal transition (EMT) via SNAI 1 and EMT associated with metastasis in a model of breast cancer progression (38). Thus, SMAD 2, which is an intracellular signal transducer and transcriptional modulator was activated by TGF- $\beta 1$, and the activated SNAI 1 can induce EMT in lung cancer (39).

A limitation of this study was the small sample size. Therefore, a larger sample size should be used in future studies for the identification of the clinical significance of IL-25 in CCA genesis, progression and prognosis.

In summary, we have demonstrated that IL-25 was expressed strongly in some, but not all of CCA cells/tissues. Further functional studies are needed to shed more light on the mechanisms by which IL-25 functions on CCA cells themselves and on the tumor microenvironment by using gene silencing and overexpression of IL-25 in CCA cell lines.

\section{Acknowledgements}

We thank Montira Janan for secretome database support at the National Center for Genetic Engineering and Biotechnology (BIOTEC), the National Science and Technology Development Agency (NSTDA). We would like to thank Professor Yukifumi Nawa for manuscript editing, along with the Publication Clinic of the Research Affairs, Khon Kaen University for grant support. We thank Dr Sittiruk Roytrakul, National Center for Genetic Engineering and Biotechnology (BIOTEC), National Science and Technology Development Agency, Pathumthani, Thailand, for suggestions on secretome interpretation, Professor Sopit Wongkham and Associate Professor Chaisiri Wongkham (Department of Biochemistry, Faculty of Medicine, Khon Kaen University, Khon Kaen 40002, Thailand), for study design comments. 


\section{Funding}

This project was supported by grants from the Khon Kean University (MRG5280033), the Centre for Research and Development of Medical Diagnostic Laboratories (CDML), Faculty of Associated Medical Sciences, Khon Kaen University and the Cholangiocarcinoma Research Institute (CARI), Faculty of Medicine, Faculty of Associated Medical Sciences, Khon Kaen University.

\section{Availability of data and materials}

The materials using and the data analysis during this study are available from the corresponding author on reasonable request.

\section{Authors' contributions}

SK performed experiments and data analysis. TP, TL, PT and SP conceived the study and revised the manuscript. AT collected CCA tissue samples and were involved in conceptualization of the study design. Methodology was completed by SK, DT, AT and PS. PS contributed to suggest histological grading. SK drafted the original manuscript. All authors have read and approved the final version of the manuscript.

\section{Ethics approval and consent to participate}

This study protocol was approved by the Human Ethics Committee of Khon Kaen University, Thailand (HE571283). Tissues and sera that were used in this study were all left-over specimens obtained during surgical treatment. Written informed consent for the use of left-over specimens for research purpose were obtained from the attending physicians prior to surgery and the original copies of the documents were kept in the CARI and KKU.

\section{Patient consent for publication}

Not applicable.

\section{Competing interests}

The authors declare that they have no competing interests.

\section{References}

1. Kamsa-Ard S, Luvira V, Suwanrungruang K, Kamsa-Ard S, Luvira V, Santong C, Srisuk T, Pugkhem A, Bhudhisawasdi V and Pairojkul C: Cholangiocarcinoma trends, incidence, and relative survival in Khon Kaen, Thailand from 1989 through 2013: A population-based cancer registry study. J Epidemiol: $1-8,2018$

2. Jusakul A, Kongpetch S and Teh BT: Genetics of opisthorchis viverrini-related cholangiocarcinoma. Curr Opin Gastroenterol 28: 258-263, 2015.

3. Blechacz B: Cholangiocarcinoma: Current knowledge and new developments. Gut Liver 11: 13-26, 2017.

4. Wongkham S and Silsirivanit A: State of serum markers for detection of cholangiocarcinoma. Asian Pac J Cancer Prev 13 17-27, 2012.

5. Tshering G, Dorji PW, Chaijaroenkul W and Na-Bangchang K: Biomarkers for the diagnosis of cholangiocarcinoma. Am J Trop Med Hyg 98: 1788-1797, 2018.
6. Sripa B, Thinkhamrop B, Mairiang E, Laha T, Kaewkes S, Sithithaworn P, Periago MV, Bhudhisawasdi V, Yonglitthipagon P, Mulvenna J, et al: Elevated plasma IL-6 associates with increased risk of advanced fibrosis and cholangiocarcinoma in individuals infected by opisthorchis viverrini. PLoS Negl Trop Dis 6: e1654, 2012.

7. Yongvanit $\mathrm{P}$, Pinlaor $\mathrm{S}$ and Bartsch $\mathrm{H}$ : Oxidative and nitrative DNA damage: Key events in opisthorchiasis-induced carcinogenesis. Parasitol Int 61: 130-135, 2012.

8. Hurst SD, Muchamuel T, Gorman DM, Gilbert JM, Clifford T, Kwan S, Menon S, Seymour B, Jackson C, Kung TT, et al: New IL-17 family members promote Th1 or Th2 responses in the lung: In vivo function of the novel cytokine IL-25. J Immunol 169: 443-453, 2002.

9. Saadoun D, Terrier B and Cacoub P: Interleukin-25: Key regulator of inflammatory and autoimmune diseases. Curr Pharm Des 17: 3781-3785, 2011.

10. Terrier B, Bièche I, Maisonobe T Laurendeau I, Rosenzwajg M, Kahn JE, Diemert MC, Musset L, Vidaud M, Sène D, et al: Interleukin-25: A cytokine linking eosinophils and adaptive immunity in churg-strauss syndrome. Blood 116: 4523-4531, 2010.

11. Fort MM, Cheung J, Yen D, Li J, Zurawski SM, Lo S, Menon S, Clifford T, Hunte B, Lesley R, et al: IL-25 induces IL-4, IL-5, and IL-13 and Th2-associated pathologies in vivo. Immunity 15 : 985-995, 2001.

12. Yin SY, Jian FY, Chen YH, Chien SC, Hsieh MC, Hsiao PW, Lee WH, Kuo YH and Yang NS: Induction of IL-25 secretion from tumour-associated fibroblasts suppresses mammary tumour metastasis. Nat Commun 7: 11311, 2016.

13. Li J, Liao Y, Ding T, Wang B, Wang B, Yu X, Chu Y, Xu J and Zheng L: Tumor-Infiltrating macrophages express interleukin-25 and predict a favorable prognosis in patients with gastric cancer after radical resection. Oncotarget 7: 11083-11093, 2016.

14. Uhlen M, Zhang C, Lee S, Sjöstedt E, Fagerberg L, Bidkhori G, Benfeitas R, Arif M, Liu Z, Edfors F, et al: A pathology atlas of the human cancer transcriptome. Science 18: 357, 2017.

15. Tummanatsakun D, Proung vitaya T, Roytrakul S, Limpaiboon T, Wongkham S, Wongkham C, Silsirivanit A, Somintara O, Sangkhamanon S and Proungvitaya S: Serum apurinic/apyrimidinic endodeoxyribonuclease 1 (APEX1) level as a potential biomarker of cholangiocarcinoma. Biomolecules 26: 413, 2019.

16. Dupont WD and Plummer WD Jr: Power and sample size calculations: A review and computer program. Control Clin Trials 11: 116-128, 1990.

17. Janan M, Proungvitaya S, Limpaiboon $T$, Proungvitaya $T$, Roytrakul S, Wongkham C, Jearanaikoon P, Chur-in S and Wongkham S: Serum adhesion molecule-1 (ICAM-1) as a potential prognostic marker for cholangiocarcinoma patients. Asian Pac J Cancer Prev 13: 107-114, 2012.

18. Kim SW, Roh J and Park CS: Immunohistochemistry for pathologists: Protocols, pitfalls, and tips. J Pathol Transl Med 50: 411-418, 2016.

19. Pierceall WE, Wolfe M, Suschak J, Chang H, Chen Y, Sprott KM, Kutok JL, Quan S, Weaver DT and Ward BE: Strategies for $\mathrm{H}$-score normalization of preanalytical technical variables with potential utility to immunohistochemical-based biomarker quantitation in therapeutic reponse diagnostics. Anal Cell Pathol (Amst) 34: 159-168, 2011.

20. Gillespie JW, Best CJ, Bichsel VE, Cole KA, Greenhut SF, Hewitt SM, Ahram M, Gathright YB, Merino MJ, Strausberg RL, et al: Evaluation of non-formalin tissue fixation for molecular profiling studies. Am J Pathol 160: 449-457, 2002.

21. De Petris L, Pernemalm M, Elmberger G, Bergman P, Orre L, Lewensohn R and Lehtiö J: A novel method for sample preparation of fresh lung cancer tissue for proteomics analysis by tumor cell enrichment and removal of blood contaminants. Proteome Sci 8: 9, 2010.

22. Ericsson $\mathrm{C}$ and Nistér M: Protein extraction from solid tissue. Methods Mol Biol 675: 307-312, 2011.

23. Lee JH, Hong CS, Lee S, Yang JE, Park Y Il, Lee D, Hyeon T, Jung S and Paik SR: Radiating amyloid fibril formation on the surface of lipid membranes through unit-assembly of oligomeric species of $\alpha$-synuclein. PLoS One 7: e47580, 2012.

24. Lowry OH, Rosebrough NJ, Farr AL and Randall RJ: Protein measurement with the folin phenol reagent. J Biol Chem 193: 265-275, 1951.

25. Kuhn M, Szklarczyk D, Pletscher-Frankild S, Blicher TH, Von Mering C, Jensen LJ and Bork P: STITCH 4: Integration of protein-chemical interactions with user data. Nucleic Acids Res 42: D401-D107, 2014. 
26. Szklarczyk D, Santos A, Von Mering C, Jensen L and Bork P STITCH 5: Augmenting protein-chemical interaction networks with tissue and affinity data. Nucleic Acids Res 44: D380-D384, 2016.

27. Gregory LG, Jones CP, Walker SA, Sawant D, Gowers KH, Campbell GA, Mckenzie AN, Lloyd CM and Lloyd CM: IL-25 drives remodelling in allergic airways disease induced by house dust mite. Thorax 68: 82-90, 2013.

28. Kaufhold S and Bonavida B: Central role of snaill in the regulation of EMT and resistance in cancer: A target for therapeutic intervention. J Exp Clin Cancer Res 33: 62, 2014.

29. Thelen TD, Green RM and Ziegler SF: Acute blockade of IL-25 in a colitis associated colon cancer model leads to increased tumor burden. Sci Rep 6: 25643, 2016.

30. Jiang Z, Chen J, Du X, Cheng H, Wang X and Dong C: IL-25 blockade inhibits metastasis in breast cancer. Protein Cell 8 : 191-201, 2017.

31. Ji Y and Zhang W: Th17 cells: Positive or negative role in tumor. Cancer Immunol Immunother 59: 979-987, 2010.

32. Furuta S, Jeng YM, Zhou L, Huang L, Kuhn I, Bissell MJ and Lee WH: IL-25 causes apoptosis of IL-25R-expressing breast cancer cells without toxicity to nonmalignant cells. Sci Transl Med 13: 78ra31, 2011.

33. Benatar T, Cao MY, Lee Y, Lightfoot J, Feng N, Gu X, Lee V, Jin H, Wang M, Wright JA and Young AH: IL-17E, a proinflammatory cytokine, has antitumor efficacy against several tumor types in vivo. Cancer Immunol Immunother 59: 805-817, 2010.

34. Mikami Y, Takada Y, Hagihara Y and Kanai T: Innate lymphoid cells in organ fibrosis. Cytokine Growth Factor Rev 42: 27-36, 2018 .
35. Corrigan CJ, Wang W, Meng Q, Fang C, Wu H, Reay V, Lv Z, Fan Y, An Y, Wang YH, et al: T-Helper cell type 2 (Th2) memory T cell-potentiating cytokine IL-25 has the potential to promote angiogenesis in asthma. Proc Natl Acad Sci USA 108: 1579-1584, 2011.

36. Wu F, Xu J, Huang Q, Han J, Duan L, Fan J, Lv Z, Guo M, Hu G, Chen L, et al: The role of interleukin-17 in lung cancer. Mediators Inflamm 2016: 8494079, 2016.

37. Lee J, Ho WH, Maruoka M, Corpuz RT, Baldwin DT, Foster JS Goddard AD, Yansura DG, Vandlen RL, Wood WI and Gurney AL: IL-17E, a novel proinflammatory ligand for the IL-17 receptor homolog IL-17Rh1. J Biol Chem 276: 1660-1664, 2001.

38. Huber MA, Azoitei N, Baumann B, Grünert S, Sommer A, Pehamberger $\mathrm{H}$, Kraut $\mathrm{N}$, Beug $\mathrm{H}$ and Wirth T: NF- $\mathrm{KB}$ is essential for epithelial mesenchymal transition and metastasis in a model of breast cancer progression. J Clin Invest 114, 2004: 569-581, 2004

39. Jayachandran A, Königshoff M, Yu H, Rupniewska E, Hecker M, Klepetko W, Seeger W and Eickelberg O: SNAI transcription factors mediate epithelial-mesenchymal transition in lung fibrosis. Thorax 64: 1053-1061, 2009. Attribution-NonCommercial-NoDerivatives 4.0 International (CC BY-NC-ND 4.0) License. 